\title{
Exploring the Motivations of BASE Jumpers: Extreme Sport Enthusiasts
}

\author{
Tara L. Allman, Robin D. Mittelstaedt, Bruce Martin \& \\ Marni Goldenberg
}

Little previous research has been conducted exploring the motivational factors that influence a person's desire to participate in extreme sports. The researchers used a means-end approach (e.g. semi-structured interviews) to explore motivations for participation in the extreme sport of BASE jumping. BASE jumping is the activity of parachuting from bridges, buildings, antennas, and cliffs, in which participants have been identified as voluntary-risk takers. The results indicated that BASE jumpers deliberately took risks as a means of becoming positively transformed, which was essential to their quality of life. The study findings hold important implications for researchers interested in further studies of extreme subcultures as well as practitioners interested in developing adventure tourism opportunities targeted toward extreme subcultures.

\section{Background}

The motivational factors that influence a person's desire to participate in extreme sports have not yet been identified. Lyng (1990) acknowledged that we do not fully understand what motivates individuals to partake in high-risk behavior. Lupton \& Tulloch (2002) have echoed this concern by recognizing that little empirical research has strived to examine the meanings attributed to high-risk behavior. Previous research has focused on some high-risk subcultures, but not on extreme sport subcultures (Katz, 1988; Lois, 2005; Lyng \& Snow, 1986; Lyng, 1990). For instance, Lyng (1990) re-analyzed a 5-year ethnographic study of skydivers (Lyng \& Snow, 1986), operationalizing the concept of edgework. The question has been explored to a 
lesser extent within the context of involvement in extreme sport subcultures. With the research on high-risk subcultures, researchers continue to be perplexed, because extreme athletes often 'claim that the experience is essentially ineffable and can be fully understood only by actually participating in it' (Lyng, 1990, p. 862). Extreme sport experiences are so deep and meaningful, they are beyond words, and leave a person mystified. Even if understanding is gained, some participants report, 'You can never fully appreciate it until you do it yourself' (Olsen, 2001, p. 146).

Instead of accepting the stereotypical view of extreme sport participants as daredevils with a death wish, previous investigations of other high-risk subcultures (Brymer \& Oades, 2009; Ferrell, 1995, 1996, 1997; Ferrell et al., 2001; Lupton, 1999; Lupton \& Tulloch, 2002; Lyng, 1990, 1993, 1998) have proposed a number of sociological explanations exploring a range of complex motivations for risk-taking behaviors that might apply to this study. Ferrell et al. (2001) examined BASE jumpers' practices of intentionally and deliberately extending the meaning of their experiences through media production. The study focused on the legal and illegal aspects of the BASE jumping subculture, examining the sensual motivations, or 'seductive appeal' (Lyng, 2005, p. 29), similar to Katz's (1988) studies on crime and deviance. But recent research on BASE jumpers has explained motivations in terms of 'positive transformation' (Brymer \& Oades, 2009). This investigation found that extreme sport participants purposefully take risks and are transformed by the common realization of humility and true courage. Additionally, Lupton \& Tulloch (2002) found that the general Australian population views risk as positive, steering away from the traditional, risk-aversive portrayal, identifying three derivatives: self-improvement, emotional engagement, and control.

This study aims to identify and clarify motivations for participation in the extreme sport of BASE jumping and, in doing so, add to previous research on high-risk subcultures. It will attempt to understand motivations for continued participation in BASE jumping using a naturalistic research design (Lincoln \& Guba, 1985; Patton, 1990). A brief discussion of the edgework literature, which has been applied to comprehend voluntary risk-taker motivations, will be followed by a discussion of means-end literature. Means-ends theory (Gutman, 1982) provides a framework for examining the outcomes that individuals associate with an activity. Consequently, it provides an effective lens through which to consider the motivations for participation in the extreme sport of BASE jumping.

\section{Edgework: The Role of Risk in the Extreme Sport of BASE Jumping}

Many sociologists have described voluntary risk-takers as edgeworkers. Thompson (1971) observed and coined the term edgework, while examining the risk-taking of notorious post-Second World War motorcycle gangs, as he anticipated continued research on the emergent risk culture. 'Essentially, edgework involves exploring the limits of one's ability and/or the technology one is using while maintaining enough control to successfully negotiate the edge' (Laurendeau, 2006, p. 584). Edgeworkers are synonymous with those who 'push the envelope', or surpass the limits of what 
has been done in the past. One can then propose that edgeworkers are, therefore, voluntary risk-takers. Lipscombe (1999) described the 'edge' as being continually challenged by the edgeworker, as it is a symbol for life versus death, or the boundary between the ordered and disordered sense of self and environment. As edgeworkers move away from their comfort zone, and closer to the edge, they begin to face their fears, perhaps experiencing feelings of discomfort and chaos (Laurendeau, 2006). In this context, chaos occurs when taking progressively greater risks in the activity, like jumping lower or more technical objects in BASE jumping (Martha \& Griffet, 2006 as cited in Laurendeau, 2008). Laurendeau (2008) suggests that voluntary risktakers crowd the 'edge' by coming as close as possible to chaos without losing control. Each edgeworker determines his or her own boundary, or edge, as each individual has his or her own subjective view of risk. Considered in terms of Varley's (2006) Adventure Commodification Continuum, crowding the edge constitutes an original adventure situated at the 'deep' end of the continuum.

Voluntary risk taking is defined as 'a behavior that involves individuals' participation in activities that they perceive to be in some sense dangerous, but are undertaken deliberately, and from choice' (Lupton \& Tulloch, 2002, p. 114). Lupton (1999) described the common acceptance of risk within our society. Dichotomous relationships exist between ideologies of risk acceptance versus risk avoidance. 'Risk avoidance in this literature is typically portrayed as rational behavior, while risktaking is represented as irrational or stemming from lack of knowledge or faulty perception' (Lupton \& Tulloch, 2002, p. 114). Some researchers (Hansson, 1989; Slovic, 1987) believed that voluntary risk-takers continued to risk, because, as they are increasingly familiarized with those risks, they become desensitized to the level of risk and need more danger to perceive their activities as risky. Other motivations include: 'for the sake of conquering fear, displaying courage, seeking excitement and thrills and achieving self actualization and a sense of personal agency' (Lupton \& Tulloch, 2002, p. 115).

Previous edgework literature contains numerous implications for the analysis of the BASE jumping subculture. In his pivotal study on skydivers as voluntary risk-takers, Lyng (1990) asserted that edgework was the key to helping us understand voluntary risk-takers' motivations. Ferrell et al. (2001) maintains that studies on voluntary risk-taking have helped to further clarify and conceptualize edgework. In 1990, Lyng developed a model that framed the practice of edgework in terms of three stages. Lois (2005) explained Lyng's model as 'powerful' - since it is able to unite the micro-social (e.g. feelings) and macro-social (e.g. institutional influence) elements of edgework. As described by Lois (2005), these stages included: (a) the preparation stage, when edgeworkers feel nervous; (b) the performing stage, during which edgeworkers 'suspend the reflexive aspect of the self, and act without thinking' (Lois, 2005, p. 147); and (c) the aftermath stage, in which edgeworkers feel 'omnipotent and self-actualized' (Lois, 2005, p. 148). Self-actualization is personified by edgeworkers who leave their everyday - 'self' - behind to 'experience themselves as instinctively acting entities, which leaves them with a purified and magnified sense of self' (Lyng, 1990, p. 860). 
Lois's (2005) study of rescue workers revealed a fourth stage in the practice of edgework: redefining feelings. She believed that her identification of this stage had little relevance to recreational risk-taking. However, since BASE jumping is an extreme sport, the fourth stage is implicit to the current study. In the redefining feelings stage, 'rescuers were able to maintain the illusion of control, despite the negative feelings they were left with after "failed" rescues' (Lois, 2005, p. 147). Many BASE jumpers have experienced logistical mishaps resulting in injury. Many even know someone within the tightly-knit BASE jumping community who has died as a result of mishap while BASE jumping. Owing to the extreme nature of the sport many avid BASE jumpers have paralleled Lois's (2005) rescuers' decision to neutralize their feelings in order to prepare themselves for their next 'mission'.

In addition, Lyng's (1990) study outlined five essential dimensions that must exist to understand edgeworkers. Lyng's (1990) dimensions included the following: (a) acknowledging the socioeconomic and historical frameworks (e.g. advancements in technology); (b) understanding the illegal/legal aspects of the edgeworker's activity, in which 'perhaps one of the sources of excitement is in fact to be able to overcome this added obstacle' (as cited in Milovanovic, 2005, p. 56); (c) comprehending lesser or greater levels of emotional intensity combined with intuitive reactions; (d) being in- and out-of-control; and (e) embracing the notion of jouissance from the French, meaning the edgeworker's ability to make sense of their activity by understanding symbols, imagery and reality.

Since the early 1980s, BASE jumping has become an alternative, extreme counterpart to its skydiving predecessor from which it evolved. Extreme sports are defined as activities in which accidents or mistakes will commonly result in severe injury or death (Brymer, 2005). BASE jumping is considered an extreme sport because of the considerably high level of risk involved in the sport. BASE is an acronym for the various free-standing structures from which an expert-level parachutist can jump: buildings, antennas (e.g. radio or television), spans (e.g. bridges), or earth (e.g. rock cliffs). In BASE jumping, the participant has only one parachute (with no back-up chute). Parachutes have been technologically designed specifically for BASE jumping, because specialized equipment is needed to successfully negotiate low altitude jumps. A typical BASE jump is between 400 to 2,000 feet, depending upon the height of the object, with a reaction time ranging from three to eight seconds. Therefore, BASE jumpers must develop expert-level skills (e.g. techniques, judgment) under dedicated mentorship and practice. The quintessential, 'One, two, three, c-ya!' is shouted as a common parting phrase as fellow BASE jumpers leave an object, commonly referred to as an exit point. A BASE number is given to individuals who jump at least once from each of the four BASE objects.

The sport of BASE jumping is criminalized to some degree by legislation prohibiting access to objects that jumpers use to pursue the sport. Examples of objects from which it is illegal to BASE jump include most buildings, antennas, spans, and some protected lands, such as the NPS, unless a sanctioned event is taking place. Because of these access restrictions, many of the most dedicated BASE jumpers are compelled to break the law to engage fully in the sport. The clandestine nature of the missions taken by these BASE jumpers (e.g. trespassing, night jumps) has resulted in negative 
public perceptions of the sport. However, Bergic (2005) has established BASE ethics to improve both safety and the image of the sport. Other BASE jumpers have expressed their concern: 'We're tired of being branded as careless, reckless outlaws' (Gutman, 2003 , p. 58). Since many BASE jumpers are keen to jump from officially forbidden objects, and with the growing popularity of the tourism industry, sanctions continue to be developed or maintained for this subculture.

BASE jumping also continues to emerge as a spectator sport, on the 'shallow' end of Varley's (2006) Adventure Commodification Continuum. Rinehart (2000) suggests that unlike mainstream sports that spread like artifacts from one culture to the next, extreme sports are simultaneously emerging and arriving. The popularity of extreme sports as a spectator sport can be attributed to the media (e.g. X-Games), technological advances, and lifestyle changes, in which tourists are motivated to escape from their everyday lives (Pomfret, 2006). Park (2004) asserts that Generation $\mathrm{Y}$ has been the coveted target market and catalyst behind the extreme sports industry, because of its impressionable age category, from $12-25$, and the fact that it encompasses over 70 million people, which is three times larger than Generation X.

\section{Means-End Theory}

Means-end theory was developed by Gutman (1982), and originated in the field of marketing as a way to determine consumer motivations for buying a specific product. Gutman (1982) explained that Rokeach's (1973) value systems research had been the driving force within this methodology to link consumer values to consumer choice of products. To improve marketing initiatives to consumers, Gutman (1982) rationalized that understanding consumer values systems can help explain consumer preferences (or valued end states). 'The motivation to consume a product therefore originates from the expected benefits the product conveys to the consumer and the expectation of achieving individual goals' (Mort \& Rose, 2004, p. 222). This is similar to Rosenberg's (1956) expectancy theory in which 'consumer actions produce consequences and consumers learn to associate particular consequences with particular aspects of a product' (Gutman \& Miaoulis, 2003, p. 106).

Means-end theory focuses on attributes, consequences, and values of the service or product (Goldenberg et al., 2005). "The "means" can be thought of as a product or service and the "ends" are the underlying consumer needs' (Gutman \& Miaoulis, 2003, p. 106). Goldenberg et al. (2002) described attributes as physical objects, services, or antecedent variables (e.g. personal experiences). The attributes of a BASE jumping experience could include: social interaction; discovery, curiosity; escape from stress; or scenic beauty, nature. Gutman (1982) identified consequences as any positive or negative outcome that is indirectly or directly related to a consumer behavior. 'Negative consequences are referred to as costs or risks, while positive consequences are frequently referred to as benefits' (Hill et al., in press, p. 10). Some positive consequences associated with a BASE jumping experience could include: adrenaline rush; camaraderie; control, overcoming fear; or commitment, passion. Some negative consequences associated with a BASE jumping experience include: financial injury 
(e.g., affording newest technology, medical costs, and travel costs); physical injury; or even death. 'Values are highly abstract consequences that summarize desired endstates of being' (Goldenberg et al., 2000, p. 212). Kahle (1983) and Verhoff et al. (1981) contributed to values research by developing the List of Values (LOV) with nine core values. This current study utilized grounded theory techniques (Corbin \& Strauss, 2007) to expand or rename some of those values to include values specific to the BASE jumping experience. 'A grounded theory is generated by themes, and themes emerge from the data during analysis, capturing the essence of meaning or experience drawn from varied situations and contexts' (Bowen, 2006, p. 2). Some examples include a sense of belonging, freedom, transference, and personal/spiritual.

As explained by Lien \& Goldenberg (in review), means-end theory aims to discover the direct relationship between attributes, consequences, and values rather than viewing them as separate entities (Gengler et al., 1995; Goldenberg et al., 2000, 2005; Gutman, 1982). The relationships or linkages between attributes, consequences, and then values are called means-end chains. This allows the researchers to follow the logical semantic sequences from the 'means' to the 'end' for each person's responses.

Means-end chains are built through laddering, a qualitative data collection process developed by Olson \& Reynolds (1983). This technique was later expanded upon by Reynolds \& Gutman (1988). According to Klenosky et al. (1993), the procedure is conducted through a series of one-on-one, open-ended interview questions, 'that gradually progresses from concrete attributes to abstract values' (Goldenberg \& Shooter, in review). The researcher begins by asking why an attribute is important, and the response will be another attribute or a consequence. The researcher continues to ask questions until the participant either provides a value statement, or no longer has a response. The laddering process is only achieved through a combination of active listening and by asking the quintessential means-end theory question, 'Why is that important to you?' (Klenosky et al., 1993, p. 365). For instance, a researcher might ask, 'In your response, I heard you mention camaraderie. Why is that important to you?' in an attempt to eventually elicit a statement reflecting a value. As explained by Goldenberg \& Shooter (in review), symbolically, and ideally, participant responses climb the ladder of abstraction, as they move from attribute to consequence to value. For example, one BASE jumping participant stated that the attribute (A) 'when you're on the edge stepping off into nothingness' (coded as Risk, edge) was important. This attribute then lead to a consequence $(\mathrm{C})$ of 'time kind of stops; my mind becomes clear' (coded as Transcendence of time), which lead to the value (V) statement 'I'm going to save my own life' (coded as Feel alive).

In increasing numbers of studies, means-end theory has been expanded beyond the field of marketing and utilized to analyze recreation and tourism services. The meansend technique was influential in examining the draw of tourist destinations (Frauman et al., 1998), interpretive services offered to tourists (Klenosky et al., 1998), ropes course challenge programs (Goldenberg et al., 2000; Haras et al., 2006), and outdoor adventure experiences (Goldenberg et al., 2002, 2005; McAvoy et al., 2006; Lien \& Goldenberg, in review). Means-end was employed in this study to better understand the motivations of individual extreme BASE jumping athletes by examining each of their personal 
attributes, consequences, and values, as evidenced in taped responses using the laddering technique. The results from this study should prove useful in the tourism industry by helping to better illustrate the benefits of participation in the sport of BASE jumping and consequently to better promote the tourism around BASE jumping events.

\section{Research Question}

Adequate support for further research on extreme sport subcultures is evidenced by a lack of literature, which influences contemporary misunderstandings of BASE jumper motivations. Therefore, a need to understand 'What value do participants get out of BASE jumping?' exists. The question posed is relevant, since it is increasingly common for risks to be taken within society (Beck, 1992; Giddens, 1998; Lupton, 1999). In fact, Varley (2006) explains that we are entering an era in which people are infatuated with risk and where adventure sports are marketed as a commodity so spectators may live vicariously through extreme sport participants. Examining BASE jumpers by applying a means-end theoretical framework is one way to clarify motivations for participating in the extreme sport of BASE jumping in a systematic manner.

\section{Methodology}

Site

Every third Saturday of October, BASE jumpers from around the world converge on the small town of Fayetteville, West Virginia, to participate in the largest BASE jumping event in the world - Bridge Day. This event attracts over 200,000 spectators and 200 local vendors annually. The State grants permission to close the New River Gorge Bridge for six hours so that BASE jumpers can use the bridge as an exit point. The span stands at 876 vertical feet, and is the second largest single arch bridge in the world. Event organizers include the: Bridge Day Commission (Fayette County Chamber of Commerce), Vertical Visions LLC, local law enforcement, the adventure tourism industry, as well as global BASE jumping and national skydiving and rappelling communities. According to Bell (2008) BASE jumper event registration and performance has risen from five to approximately 450 since its inception in 1980. Bridge Day draws seasoned BASE jumpers and is also a popular gateway venue for many skydivers to take their first plunge as a BASE jumper. In 2008, 25\% of registered jumpers were making their first BASE jump. If novices fail to land in the landing zone, stationed rescue boats and personnel will pull novices out of the water and to safety. Parachutists must log a minimum of 100 skydives and attend a First Jump Course (FJC), (or be trained by an approved mentor), prior to event registration. A total of 1,062 jumps in 7 hours were made at Bridge Day 2008.

\section{Sample}

Data were collected during Bridge Day events, in October 2008, via convenience sampling. The primary researcher arranged a meeting with the Bridge Day 
Commission's Media Coordinator at the Fayette County Chamber of Commerce prior to commencement of Bridge Day 2008. The meeting was used to discuss all registered researchers' authorization to access BASE participants through special privileges, such as Media Passes. The Bridge Day Commission was supportive in providing local information and specific details of the event. Intimate access allowed researchers on the bridge to interview, one hour prior to the start of BASE jumping on Saturday, with only media and scheduled jumpers. It also permitted researchers to ride a shuttle to and from designated media areas above and below the bridge to facilitate interception of BASE jumpers at the exit point and landing zone. Other interviews took place two days prior to Bridge Day, at pre-Bridge Day social events held at the Oak Hill Holiday Inn.

According to in-person conversations with a local BASE jumper in West Virginia, BASE jumpers could be distinguished from skydivers at Bridge Day by the following characteristics: they packed their own rigs and could often be seen training other novice jumpers how to pack their rigs, BASE jumpers tended to be more meticulous when packing their rigs (e.g. obvious elite skills), and they were often less willing than skydivers to talk openly about their subculture. Interviewers approached participants based on these observable criteria. For the purposes of this study, BASE jumpers are characterized as those interviewed who identified themselves as part of the BASE jumping subculture, or as both a skydiver and a BASE jumper. BASE jumping participants met the minimum requirements for this analysis if they had a total of three jumps that included objects other than at Bridge Day (e.g. ASE). Examples of other objects included natural cliffs, skyscrapers, or antennas. However, numerous BASE jumpers in this study had recorded over 200 jumps.

The original sample size was $n \quad 98$ of the 383 (or 25.6\%) registered jumpers in attendance, but only those who met the minimum BASE jumper criteria described above were retained. A number of other interviews were eliminated due to poor sound quality or inconsistencies in following methodology protocol, leaving a final total sample size of $n$ 54. This number represents an adequate sample size, since means-end literature requires a minimum of 40 quality interviews. The primary researcher discarded several interviews because either researchers were not consistent in following the interview protocol, or the interviews did not reveal enough depth (e.g. a researcher elicited no value statements from the interviewee). Future researchers should allow for more time, and a more rigorous procedures for selecting and training research assistants. Researchers also conducted a number of interviews at pre-Bridge Day social events, during which some interviewees were under the influence of alcohol. Researchers mitigated this constraint by conducting interviews early in the evening to assure reliability of the data. Despite all these challenges, researchers were able to exceed the minimum sample size of 40 quality interviews.

\section{Instrument and Procedures}

Prior to the study, research assistants were recruited to help conduct a minimum of 40 quality interviews in less than three days. There were a total of nine researchers, with one primary researcher, two co-authors' assistance, and six research assistants. Two 
mandatory trainings were conducted to assure consistency while executing the methodology. These trainings included identification of anticipated concerns, discussion of how to mitigate concerns (e.g. specifically recruiting BASE jumpers, performing consistent methodology, avoiding tangents, properly operating DVRs), as well as mock interview practice.

All interviews were conducted in person using an interview script. Most interviews were 5-20 minutes in length. Researchers sought to administer interviews to jumpers who specifically self-identified with the BASE jumping subculture. The interview script included both demographic information and open-ended questions. Respondents were asked to name their top three outcomes obtained from the extreme sport of BASE jumping, ('Think about the things you learn and the outcomes you receive from participating in the extreme sport of BASE jumping.'). Once listed, the outcomes were ranked from most to least important, and then each outcome was queried separately. Respondents were asked why that outcome was important to them. The respondents' statements were restated by the interviewer to clarify that their meaning was fully apprehended (e.g. 'I heard you mention that friends are important to you.'). Once clarification was made, the interviewer would ask, again, 'Why is that important to you?' This pattern of active listening and questioning repeated until the respondent was no longer able to elicit a response.

\section{Analysis}

Data collected during the interviews required a series of analyses. First, $80 \%$ of the interviews were fully transcribed by the primary investigator, while $20 \%$ were transcribed by the research assistants. A total of 293 pages of transcriptions were derived from the interviews. Once the interviews were fully transcribed, ladders were derived by pulling out key phrases from the interviews. The ladders were coded based on Kahle's (1983) List of Values (LOV) as a guideline, and additional codes were derived inductively (Patton, 1980), resulting in the expansion of the original LOV. Once the data were organized into ladders and an initial coding scheme was formulated, an independent coder reanalyzed $31.5 \%\left(\begin{array}{ll}n & 17\end{array}\right)$ of the data to verify the accuracy of the codes created. To accomplish this, the independent coder was given the original transcriptions to create ladders by pulling out key phrases. These ladders were also separately coded. Researchers then met to clarify their coding schemes, since previous discussions established that many codes (themes) overlapped. As predicted, many codes were used interchangeably, because identical quotes were pulled from transcriptions by both researchers. The researchers made the mutual decision to merge some codes into one concept, and then calculated the first intercoder reliability $(86.8 \%)$. Neuendorf (2002) states that reliability coefficients of 0.80 or greater are acceptable as a baseline.

Next, the coded ladders were entered into Laddermap software (Gengler \& Reynolds, 1995). This software assembles content categories from key words in the list of prominent attributes, consequences, and values. A second coding was then conducted by an independent party on $100 \%$ of the data once the codes were stripped. Intercoder reliability and 
validity was determined to be $85.75 \%$ following the second coding. Two of the researchers examined the codes assigned originally and by the intercoder to make any needed changes. Once the changes were implemented, an implication matrix was derived from this process, which Klenosky et al. (1998) described as a summary of the frequency which each attribute, consequence or value was associated to other concepts within the respondents' ladders. Lastly, the means-end associations between concepts were graphically portrayed (Gengler et al., 1995, p. 245) in a Hierarchical Value Map (HVM) (Figure 1), using approximately $92 \%$ of the data, (a level 2 cut-off). This cutoff value was used to provide a clearer HVM, since many connections were apparent.

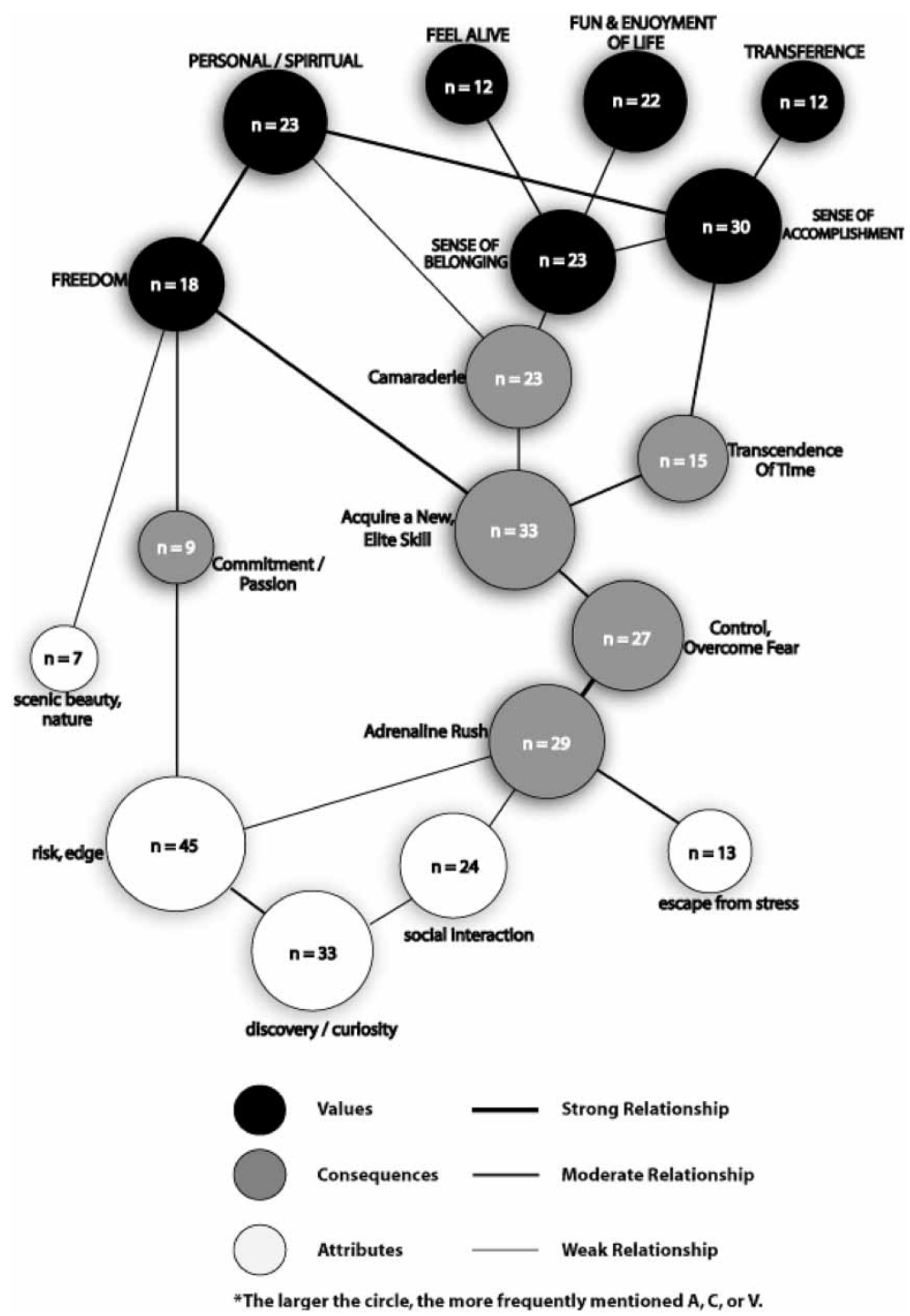

Figure 1 Hierarchical Value Map for BASE Jumpers ( $n$ 54). 
HVMs can be thought of as cognitive structure maps (Gengler et al., 1995, p. 245), in which respondents' thought processes (or means-end chains) can be observed. HVMs were structured to depict the frequency and strength of the relationships between attributes, consequences, and values. Each concept (e.g. attribute, consequence, and value) is represented by a circle. Attributes are represented by white circles, and all lower case labels. Consequences are represented by gray circles, and have only the first letter of the label capitalized. Values are represented by black circles, and all upper case labels. Larger circles symbolize that a higher frequency of respondents identified that particular concept. Stronger relationships between concepts are portrayed by thicker lines connecting circles (concepts), while thinner lines show weak relationships.

\section{Results}

A final total sample size of 54 respondents provided the data for this study. Participant demographics were verified using descriptive statistics. The sample was comprised of $85.2 \%\left(\begin{array}{ll}n & 46\end{array}\right)$ males and $14.8 \%\left(\begin{array}{ll}n & 8\end{array}\right)$ females, following the demographics of the BASE jumping population. During the 2008 event, the Bridge Day Commission confirmed that 50 jumpers (or 13\%) were female jumpers. The average age was 34.9 years old, with a standard deviation of about 9 years. Examination of the data confirmed two dominant participant age ranges, from $24-28$ years old $\left(\begin{array}{ll}n & 15\end{array}\right)$ and $36-40$ years old ( $n$ 15) (see Figure 2). The sample had 43 diverse occupations, with 9.3\% $\left(\begin{array}{ll}n & 5\end{array}\right)$ students and 90.7\% ( $n$ 49) other occupations. Careers ranged from BASE jumper manufacturers and skydiving instructors to air traffic controllers, engineers, mechanics, and professionals in the medical field. Further statistics revealed that $92.6 \%$ ( $n$ 50) of the sample resided within the United States, while 7.4\% ( $n$ 4) resided in Canada, Poland, Slovenia, and Bermuda; 15 total countries were represented at the 2008 event. The regional geographical breakdown of the 50 respondents from the United States included 38\% ( $n$ 19) from the Southeast, 24\% ( $n$ 12) from the Northeast, $12 \%\left(\begin{array}{ll}n & 6\end{array}\right)$ from both Intermountain and Central states, while $14 \%$ ( $n$ 7 7) of respondents declined to provide regional information.

Eighteen content categories were obtained from the analysis: five attributes (mostly antecedent variables), six consequences, and seven values. The HVM (see Figure 1) was created from responses BASE jumpers gave with regard to what motivated them to participate in the sport and why those experiences were important to them. Attributes are denoted by white circles, consequences by gray circles, and values by black circles. Some of the most commonly mentioned attributes include: Risk, Edge ( $\left.\begin{array}{ll}n & 65\end{array}\right)$, in which participants express fear elicited prior to jumping, often cite 'standing on the edge', feeling 'unique' or 'special', 'doing what man was not intended to do', or 'cheating death'; Discovery/Curiosity ( $n$ 39), in which participants describe an initial desire stemming from their past, stating, 'I always dreamed about doing it', or they started jumping 'to learn something'; and Social Interaction ( $n$ 24), in which BASE jumpers 'found like-minded people' or they get to 'meet lots of cool people', and enjoy socializing with this group. Other cited attributes were Escape from Stress

15) and Scenic Beauty, nature ( $n$

$7)$. 


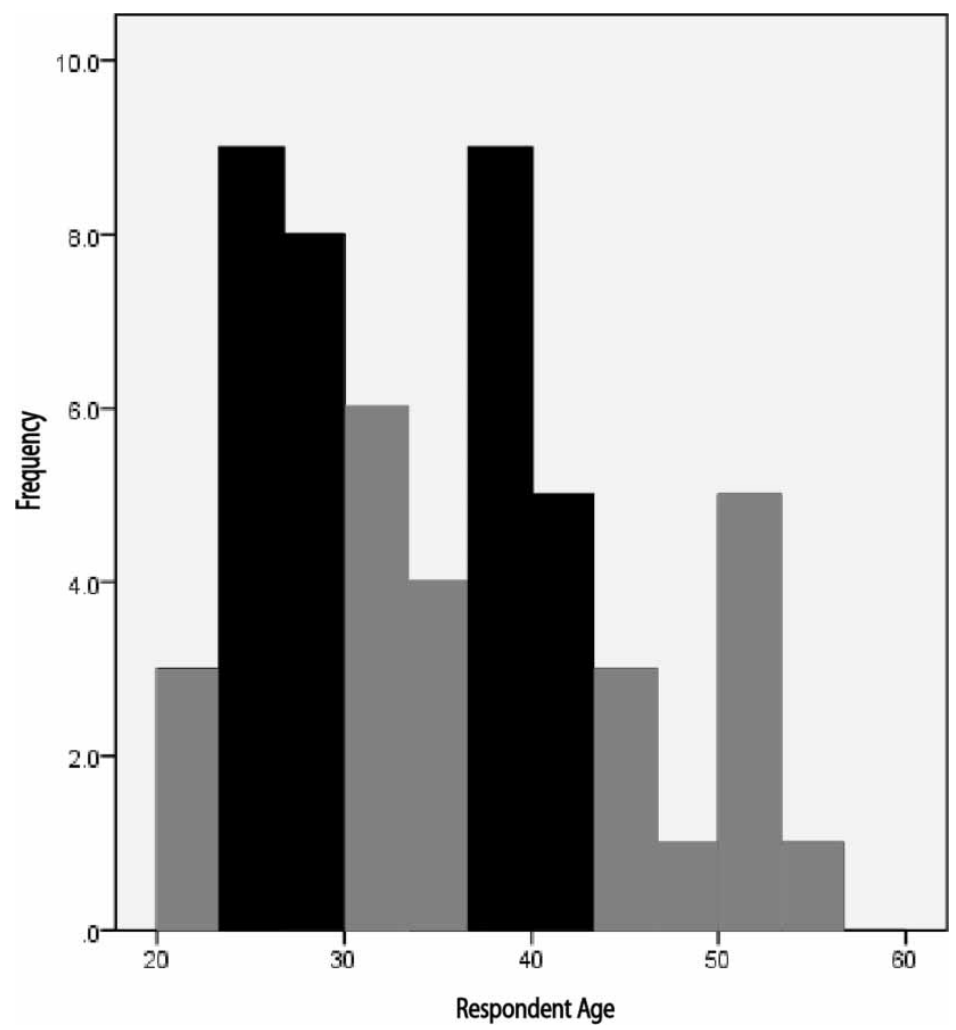

Figure 2 BASE Jumper Age Distribution, Depicting Two Dominant Age Ranges: (a) 24$28(n \quad 15)$ and (b) 36-40 ( $n$ 15).

The predominant consequences included: being able to Aquire a New, Elite Skill ( $n$ 43), in which participants describe their personal growth in skills (above and beyond skydiving), 'being able to deal with or fix intense situations through decisions' or enjoyment of 'logistical challenges'; an Adrenaline Rush ( $n$ 30), in which the words 'excitement', 'rush' or 'emotional overload' were used; being in Control, or Overcoming Fear ( $n$ 30), in which participants 'control emotions' or 'face fears'; and Camaraderie ( $n$ 23), in which BASE jumpers cite 'sharing the experience with close friends' or feel 'supported from other BASE jumpers'. Other cited consequences were Transcendence of Time $(n$ 16) and Commitment/Passion ( $\left.\begin{array}{ll}n & 9\end{array}\right)$.

The primary values include: a Sense of Accomplishment $\left(\begin{array}{ll}n & 40\end{array}\right)$, in which participants 'feel successful', experience a 'sense of empowerment', or gain 'self-confidence'; Sense of Belonging ( $n$ 25), in which respondents feel 'accepted' as 'part of a community', 'a sense of identification with others', or 'sharing an 'understanding' about each others' experiences without having to talk about it'; Personal/Spiritual ( $n$ 25), in which respondents mention 'feeling a connection with something higher than themselves', 'enlightenment' of 'what is really important', 'realization of their 
capabilities', or 'seeing things from a new perspective'; and Fun and Enjoyment of Life ( $n$ 25), in which BASE jumpers cite that they 'have fun doing it'. Other cited values include Freedom ( $n$ 21), Transference of lessons learned BASE jumping into everyday life ( $n$ 14), and Feeling Alive ( $n$ 13).

The most significant associations, or strongest associations between attributes, consequences and values, include those connections between: (a) Escape from Stress and Adrenaline Rush; (b) Adrenaline Rush and Control/Overcome Fear; and (c) Control/ Overcome Fear and Acquire a New, Elite Skill. Acquiring a New, Elite Skill was strongly linked between Freedom and Transcendence of Time. Other strong relationships existed between Freedom and Personal/Spiritual, as well as Transcendence of Time and Sense of Accomplishment. For example, one BASE jumping participant stated that the attribute (A) 'with work, with stress, with pressure, with everything that goes on in life' (coded as Escape from stress) was important. This attribute then lead to a consequence (C) 'Adrenaline rush'. This consequence lead to another consequence (C) 'just a way to clear all of that out of your mind' (Transcendence of time), which lead to the (V) statement 'It makes me feel alive' (Feel alive).

Sense of Accomplishment showed strong relationships between both Personal/ Spiritual and Transference. Strong links occurred between Risk/Edge and Commitment/Passion and Commitment/Passion and Freedom. For example, one BASE jumping participant stated that the attribute 'you pass a test, could you spell a word right, could you drag a car down the road, I mean those are all very elementary things in my opinion, but these things are at my limits, you know? This is the forefront of my existence' (coded as Risk/edge) lead to consequence (C) 'commitment/passion'. This consequence lead to another consequence 'evolving ... and you put that knowledge to the test' (Acquiring a new, elite skill), which lead to the Value statement 'You can accept the fact that it is okay to do this. You have faith in your gear, your skill, your knowledge, of this moment that you're interacting with' (coded as Freedom). Other relationships showed the attributes Discovery/Curiosity and Risk/Edge were strongly linked. Commonly, BASE jumpers continued participation in the sport because they valued Freedom, Personal/Spiritual aspects of BASE jumping, gaining a Sense of Accomplishment, and Transference.

\section{Discussion}

This research was an exploratory study in which motivational factors for participation in the extreme sport of BASE jumping were examined. Results of the current study were illustrative in nature, indicating a wide range of positive motivations for continued participation in BASE jumping. The most prevalent motivations included: Aquire a new, elite skill; Sense of accomplishment; Adrenaline rush; Control, overcome fear; Sense of belonging; and Personal/Spiritual. These findings challenge the stereotypical view of BASE jumpers as daredevils with a death wish. Instead, these personal motivations are congruent with findings from previous studies (Brymer \& Oades, 2009; Lupton \& Tulloch, 2002; Maeland, 2002) in which high-risk athletes deliberately took risks as a means of becoming positively transformed. The results of those 
studies describe the outcomes of participating in high-risk pursuits as essential to a person's overall quality of life.

The results from this study support the results of previous edgework literature (Ferrell et al., 2001; Lois, 2005; Lupton \& Tulloch, 2002; and Lyng, 1990, 1993, 1998), which recognized a range of complex motives for participation in riskseeking behaviors. As such, this study furthers an understanding of the complex relations between thought processes and risk-taking actions demonstrated by the BASE jumping subculture. Overall results also revealed the presence of the significant four stages of edgework: (a) preparation stage; (b) performing stage; (c) aftermath stage; and (d) redefining feelings stage, as cited by Lyng (1990) and Lois (2005). Since identity formation is implicit to high-risk subcultures, further studies related to edgework should continue to investigate how identity formation differs between men and women. Lois (2005) recognized that both men and women experience physical and emotional edgework, but that they call upon individualized skills and techniques in order to complete all four stages of edgework. While it is important to recognize that men and women engage in edgework differently, it is equally important for further research to explore specifically how men and women engage in edgework differently.

Since means-end theory was successful in examining the outcomes of the BASE jumping subculture, it also demonstrates the potential to use the results to develop tourism opportunities targeted toward extreme subcultures. Similarly, Goldenberg \& Shooter (in review) noted how the skateboarding subculture was previously described as rebellious and defiant, but, with the popularity of skate parks, the sport evolved as a positive outlet and an opportunity for youth (personal) development. While BASE jumpers act on the 'deep' end of Varley's (2006) Adventure Commodity Continuum due to the high level of actual risk involved in the sport, skateboarders act on the 'shallow' end of the spectrum. However, the comparison between the two groups demonstrates how positive portrayals of previously misunderstood groups (e.g. skateboarders and BASE jumpers) can contribute to a new understanding of how these sports positively transforms participants (Kelly et al., 2005). Consequently, the results of this study can assist professionals in the adventure tourism industry by increasing their awareness of the benefits of BASE jumping participation and reframing the image of the sport. For example, this research can help West Virginia's tourism industry to promote the Bridge Day event in a more positive light.

A report entitled 'The Economic Impact of the Hatfield-McCoy Trail System in West Virginia' (Center for Business and Economic Research, 2006) identified tourism as the third largest industry in West Virginia. The report indicated that this is largely due to the economic opportunities related to outdoor recreation and sport. Witt \& Fletcher (2005) also found that tourism was central to West Virginia's economy, as one of the fastest growing industries in terms of economic contribution (4\% annual growth) and growth of employment (15.6\% annual growth) between 1980 and 2005. Other major industries in West Virginia, such as mining and manufacturing, showed a decline or slow growth during the same time period. Recent economic 
impact studies continue to provide support for the adventure tourism industry. Sizemore (2009) stated that the travel and tourism industry supported 44,000 jobs and earnings of $\$ 912$ million during 2008. Bridge Day is a major contributor to West Virginia tourism, as over 200,000 spectators, 200 vendors, and 450 participants attend the event annually. This festival attracts a multitude of user groups, including not only BASE jumpers, but also hikers, rafters, kayakers, and rappellers. Understanding the desires of BASE jumpers can facilitate more focused marketing initiatives and thus better promote this tourism event in West Virginia. In addition, means-end analysis would be useful to determine the best way to identify the motivations of spectators of extreme adventure sports and to market to this group accordingly.

The most difficult challenge of this study was the time constraints of the event, in which nine researchers had to implement the methodology in a consistent manner. On occasion, the tangential interviews were discarded because they compromised the consistency of the methodology. Future researchers should allow for more time to complete similar studies. If an extended time frame is not possible, researchers should use more rigorous procedures for selection and training of research assistants. Research assistants would then be prepared to conduct a larger number of consistent and high quality interviews. It is recommended that no more than three research assistants conduct the interviews. Hill et al. (in press) also suggested utilizing a quasi-qualitative scale to save time, since conducting personal interviews is time consuming. A survey such as this could be posted on numerous online BASE jumping forums (e.g. BLiNC magazine, basejumper.com, and so on). Distributing surveys in this manner could provide worldwide access to an otherwise isolated BASE jumping subculture, in which open discussions on the latest news, trends, equipment, and events are posted. Online surveys might also make it easier to distinguish between skydivers and BASE jumpers, allowing BASE jumpers to respond at their own leisure.

It was also difficult to develop a rapport with the BASE jumpers within such a limited time frame in the setting provided. Researchers were not a part of the elite BASE jumping subculture, which made it difficult for researchers to distinguish between BASE jumpers and skydivers. Prior to Bridge Day, the primary researcher met with a Fayetteville BASE jumper and discussed the best way to recognize and approach a BASE jumper. Bogdan \& Taylor (1975) discussed the importance of solidifying your relationship with the subject before exploring their feelings. Had more of the researchers been able to make this site visit, it might have somewhat increased their preparation and awareness of the BASE jumping subculture. Despite this challenge, respondents were inclined to talk in-depth about the deeper meanings associated with their BASE jumping experiences. Researchers should explore explanations for the demonstrated insightfulness of the BASE jumping subculture, as well as reasons some persons within the subculture refused to be interviewed.

Additional suggestions for future research include visiting more BASE jumping sites. More and more extreme sport events happen worldwide, as BASE jumpers are granted access to BASE objects (e.g. year-round legal BASE jumping at the Perrine Bridge in Twin Falls, Idaho) or new venues (e.g. Malaysia's annual KL Tower International Jump and Merdeka Circuit, UK's Bedford River Festival, Colorado's Royal 
Gorge Go Fast Games, privileged access to Angel Falls in Venezuela, the Turkey Boogie in Moab, Utah, and the Perrine Memorial Day Boogie in Idaho). Conducting research at multiple sites would allow researchers to get a more intimate insight into BASE jumper motivations and the current trends (e.g. motivations for sport spectator participation) of the adventure tourism industry.

It is essential to examine BASE jump motivation, in order to accurately interpret the true essence of the subculture. Contemporary stereotypes that portray BASE jumpers negatively do not match the motivations cited by respondents in this study. BASE jumping is a sport that is continually evolving, through advancements in skills, equipment, and technology, by establishing ethical practices, and through dedicated mentorship. Practitioners should market to this extreme sport subculture through the lens of providing opportunities for: overcoming obstacles, transferring lessons learned to everyday life, acknowledging personal and spiritual rejuvenation, encouraging fun and enjoyment of life, feelings of freedom peace and acceptance, and building a social community.

Recognizing attributes that attract parachutists to the extreme sport of BASE jumping might also provide insights as to why individuals choose to participate. It is equally important to understand the values held by BASE jumping participants. Results of this study illustrate benefits from participation, or claims that positive outcomes are gained by BASE jumping participants. Identifying outcomes associated with BASE jumping allows the adventure tourism industry to perform outcome-based thinking, marketing intentionally with a focus on the positive transformative experience professed by participants. In addition, the extreme sport of BASE jumping offers opportunities for participants to explore their personal freedoms, confirming their belief system by finding what it is they value most about life.

\section{References}

Beck, U. (1992). Risk society: towards a new modernity. Newbury Park, CA: Sage.

Bell, J. (2008). Bridge day statistics. Retrieved April 30, 2009 from http://www.bridgeday.info/stats/ bdaystats.pdf

Bergic, T. (2005). BASE ethics. Retrieved 22 February 2009 from http://www.snakeriverbase.com/ library.html

Bogdan, R., \& Taylor, S. (1975). Introduction to qualitative research methods: a phenomenological approach to the social sciences. New York: Wiley.

Bowen, G. (2006). Grounded theory and sensitizing concepts. International Journal of Qualitative Methods, 5(3), Article 2.

Brymer, E., \& Oades, L.G. (2009). Extreme sports: a positive transformation in courage and humility. Journal of Humanistic Psychology, 49(1), 114126.

Brymer, G.E. (2005). Extreme dude! A phenomenological perspective on the extreme sport experi ence. Doctoral Dissertation, University of Wollongong. Retrieved Wednesday, 24 October 2007 from http://www.library.uow.edu.au/adt NWU/uploads/approved/adt NWU20060508.145406/ public/02Whole.pdf

Center for Business and Economic Research (2006). The economic impact of the Hatfield McCoy Trail System in West Virginia: Final report. Huntington: Marshall University Center for Business and Economic Research. Retrieved October 23, 2009 from www.marshall.edu/cber/research/ Hatfield McCoy Study.pdf 
Corbin, J.M., \& Strauss, A.C. (2007). Basics of qualitative research: techniques and procedures for devel oping grounded theory. London: Sage.

Ferrell, J. (1995). Urban graffiti: Crime, control, and resistance. Youth and Society, 27(1), 7392.

Ferrell, J. (1996). Crimes of style: urban graffiti and the politics of criminality. Boston, MA: Northern University Press.

Ferrell, J. (1997). Criminological verstehen: inside the immediacy of criminality. Justice Quarterly, 14(1), 587608.

Ferrell, J., Milovanovic, D., \& Lyng, S. (2001). Edgework, media practices, and the elongation of meaning: a theoretical ethnography of the Bridge Day event. Theoretical Criminology, 5(2), 177202.

Frauman, E., Norman, W.C., \& Klenosky, D.B. (1998). Using Means end theory to understand visitors within a nature based interpretive setting: a comparison of two methods. Tourism Analysis, 2, 15.

Gengler, C.E., \& Reynolds, T.J. (1995). Laddermap. Camden, NJ: Means End Software.

Gengler, C.E., Klenosky, D.B., \& Mulvey, M. (1995). The graphical representation of means end results. International Journal of Research and Marketing, 12(3), 245256.

Giddens, A. (1998). Risk society: the context of British politics. In J. Franklin (Ed.), The politics of risky society, pp. 23 34. Cambridge: Polity Press.

Goldenberg, M.A., \& Shooter, W. (In review). Skateboard park participation: a means end analysis. Journal of Youth Development

Goldenberg, M.A., Klenosky, D.B., O’Leary, J.T., \& Templin, T.J. (2000). A means end investigation of ropes course experiences. Journal of Leisure Research, 32(2), 208224.

Goldenberg, M.A., Klenosky, D., McAvoy, L., \& Holman, T. (2002). Using means end theory to understand the outdoor adventure experience. Journal of Research in Outdoor Education, 6, 4047.

Goldenberg, M.A., McAvoy, L., \& Klenosky, D.B. (2005). Outcomes from components of an Outward Bound experience. Journal of Experiential Education, 28(2), 123146.

Gutman, J. (1982). A means end chain model based on consumer categorization processes. Journal of Marketing, 46, 6072.

Gutman, B. (2003). Being extreme: thrills and dangers in the world of high risk sports. Kensington: Citadel Press.

Gutman, J., \& Miaoulis, G. (2003). Communicating a quality position in service delivery: an appli cation in higher education. Managing Service Quality, 13(2), 105111.

Hansson, S. (1989). Dimensions of risk. Risk Analysis, 9, 107112.

Haras, K., Bunting, C.J., \& Witt, R.A. (2006). Meaningful involvement opportunities in ropes course programs. Journal of Leisure Research, 38(3), 339362.

Hill, E., Goldenberg, M., \& Freidt, B. (In press). Benefits of hiking: a means end approach on the Appalachian Trail. Journal of Unconventional Parks, Tourism, \& Recreation Research.

Kahle, L.R. (Ed.) (1983). Social values and social change: adaptation of life in America. New York: Praeger.

Katz, J. (1988). Seductions of crime: moral and sensual attractions in doing evil. New York: Basic Books.

Kelly, D.M., Pomerantz, S., \& Currie, D. (2005). Skater girlhood and emphasized femininity: 'You can't land an Ollie properly in heels'. Gender Education, 17(3), 229248.

Klenosky, D., Gengler, C., \& Mulvey, M. (1993). Understanding the factors influencing ski destina tion choice: a means end analytic approach. Journal of Leisure Research, 25(4), 362379.

Klenosky, D.B., Frauman, E., Norman, W.C., \& Gengler, C.E. (1998). Nature based tourists' use of interpretive services: a means end investigation. Journal of Tourism Studies, 9(2), 2636.

Laurendeau, J. (2006). 'He didn't go in doing a skydive': sustaining the illusion of control in an edge work activity. Sociological Perspectives, 49(4), 583605.

Laurendeau, J. (2008). 'Gendered risk regimes': a theoretical consideration of edgework and gender. Sociology of Sport Journal, 25, 293309. 
Lien, M., \& Goldenberg, M. (In review). Outcomes of college wilderness orientation programs. Journal of Experiential Education.

Lincoln, Y.S., \& Guba, E.G. (1985). Naturalistic inquiry. London: Sage.

Lipscombe, N. (1999). The relevance of peak experience to continued skydiving participation: a qualitative approach to assessing motivations. Leisure Studies, 18(4), 267288.

Lois, J. (2005). Gender and emotion management in the stages of edgework. In S. Lyng (Ed.), Edgework: the sociology of risk taking, pp. 117 152. New York: Routledge.

Lupton, D. (1999). Risk. New York: Routledge.

Lupton, D., \& Tulloch, J. (2002). 'Life would be pretty dull without risk': voluntary risk taking and its pleasure. Health, Risk, and Society, 4(2), 113124.

Lyng, S. (1990). Edgework: a social psychological analysis of voluntary risk taking. The American Journal of Sociology, 95(4), 851886.

Lyng, S. (1993). Dysfunctional risk taking: criminal behavior as edgework. In N.J. Bell \& R.J. Bell (Eds.), Adolescent risk taking, pp. 107 130. Newbury Park, CA: Sage.

Lyng, S. (1998). Dangerous methods: Risk taking and the research process. In J. Ferrell \& M.S. Hamm (Eds.), Ethnography at the edge, pp. 221 251. Boston, MA: Northeastern University Press.

Lyng, S. (2005). Sociology at the edge: social theory and voluntary risk taking. In S. Lyng (Ed.), Edge work: the sociology of risk taking, pp. 17 49. New York: Routledge.

Lyng, S., \& Snow, D.A. (1986). Vocabularies of motive and high risk behavior: the case of skydiving. Advances in Group Processes, 3, 15779.

Maeland, S. (2002). B.A.S.E. En studie I samtidskultur. Ekstremt friluftsliv. Eksistensielle dilemmaer. Sublime opplevelser [B.A.S.E. A study in contemporary culture. Extreme outdoor life, existen tial dilemmas, sublime experiences] Master thesis. Hovedfagsoppgave, Bo: Hogskolen i Telemark.

Martha, C., \& Griffet, J. (2006). Le BASE jump, le jeu le plus serieux du monde [BASE jumping: the most serious play in the world]. Ethnologie Francaise, 36(4), 635642.

McAvoy, L., Holman, T., Goldenberg, M., \& Klenosky, D. (2006). Wilderness and persons with dis abilities: Transferring the benefits to everyday life. International Journal of Wilderness, 12(2), 2331.

Milovanovic, D. (2005). Edgework: A subjective and structural model of negotiating boundaries. In S. Lyng (Ed.), Edgework: the sociology of risk taking, pp. 51 71. New York: Routledge.

Mort, G., \& Rose, T. (2004). The effect of product type on value linkages in the means end chain: implications for theory and method. Journal of Consumer Behavior, 3(3), 221234.

Neuendorf, K.A. (2002). The content analysis guidebook. Thousand Oaks, CA: Sage.

Olsen, M. (2001). Women who risk: profiles of women in extreme sports. New York: Hatherleigh Press.

Olson, J.C., \& Reynolds, T.J. (1983). Understanding consumers' cognitive structures: implications for advertising strategy. In L. Percy \& A. Woodside (Eds.), Advertising and consumer psychology, 1, pp. 77 90. Lexington, MA: Lexington Books.

Park, H. (2004). Analyzing motivational factors of action sports participants. Unpublished master's thesis, Washington State University, Pullman, Washington. Retrieved 13 October 2007 from www.dissertations.wsu.edu/Thesis/Fall2004/h park 122104.pdf

Patton, M.Q. (1980). Qualitative evaluation methods. Beverly Hills, CA: Sage.

Patton, M.Q. (1990). Qualitative evaluation and research methods, 2nd edn. London: Sage.

Pomfret, G. (2006). Mountaineering adventure tourists: a conceptual framework for research. Tourism Management, 27, 113123.

Reynolds, T., \& Gutman, J. (1988). Laddering theory, method analysis, and interpretation. Journal of Advertising Research, 28(1), 3439.

Rinehart, R.E. (2000). Emerging arriving sport: alternatives to formal sports. In J. Coakley \& E. Dunning (Eds), The handbook of sport studies, pp. 504 519. London: Routledge.

Rokeach, M.J. (1973). The nature of human values. New York: Free Press. 
Rosenberg, M.J. (1956). Cognitive structure and attitudinal effect. Journal of Abnormal and Social Psychology, November, 367-372.

Sizemore, T. (2009). Study shows growth of visitors' economic impact in West Virginia. Retrieved 23 October 2009 from http://www.wvcommerce.org/news/story/Study-shows-growth-ofvisitors-economic-impact-in-West-Virginia/475/default.aspx

Slovic, P. (1987). Perception of risk. Science, 236, pp. 280-285.

Thompson, H.S. (1971). Fear and loathing in Las Vegas: a savage journey to the heart of the American dream. New York: Warner.

Varley, P. (2006). Confecting adventure and playing with meaning: the adventure commodification continuum. Journal of Sport Tourism, 11(2), 173-194.

Verhoff, J., Douvan, E., \& Kulka, R.A. (1981). The inner American. New York: Basic Books.

Witt, T.S., \& Fletcher, M. (2005). Tourism and the West Virginia economy. Morgantown: West Virginia University Bureau of Business and Economics. Retrieved 23 October 2009 from www.be.wvu. edu/comm./tourism.pdf 